\title{
THE BASAL SECRETION OF PEPSIN BY THE HUMAN STOMACH ${ }^{1}$
}

\author{
BY HENRY D. JANOWITZ AND FRANKLIN HOLLANDER
}

\author{
(From the Gastroenterology Research Laboratory, The Mount Sinai Hospital, \\ New York, N. Y.)
}

(Submitted for publication November 23, 1951 ; accepted January 8, 1952)

The basal secretion of the human stomach represents the juice secreted in the absence of all intentional and avoidable stimuli (1). The measurement of this phase of gastric secretion has been suggested by Bloomfield, Chen, and French as the simplest and most useful procedure in the study of clinical gastric physiology (2). These investigators demonstrated that the basal gastric secretion of hydrochloric acid was significantly greater in patients with duodenal ulcer than the values obtained in control subjects and in patients with gastric ulcer. Evidence regarding the basal secretion of pepsin however does not exist. Indeed there are considerable and serious deficiencies in our knowledge of the mechanism of pepsin secretion in man. This becomes especially clear if the meager existing evidence is contrasted with the extensive information which is now available regarding the mechanics of hydrochloric acid secretion (3). The present study was therefore designed to obtain quantitative evidence on the rate of secretion of pepsin by the human stomach under basal conditions, as the first step in a systematic study of the mechanics of this process. Subjects with a wide range of secretory activity, and a variety of clinical conditions, were studied. To extend the value of the information being collected, the simultaneous secretion of acid was also measured. The results obtained in control and peptic ulcer groups, and especially the correlation between the rates of enzyme and acid output, are presented in this report.

\section{METHODS}

Sixty-one subjects with a considerable range of gastric secretory activity were employed in this study. Of these, 21 were individuals with clinically active duodenal ulcer, confirmed either by the roentgen demonstration of an ulcer niche, or by surgical resection. Four patients had benign gastric ulcers proven by histological examination following surgical resection, five had gastric carcinoma,

1 This study was conducted with the aid of grants from the Altman Foundation and Wyeth, Incorporated. and five had addisonian pernicious anemia. The remaining 26 individuals, the control group, had no gastric disturbances or demonstrable lesions.

All subjects had subsisted on a liquid diet without any medication or sedation on the day preceding the experiments. All food was withheld following the evening meal. The subjects were then studied 18 hours later, in the fasting state. The spontaneous (non-stimulated) gastric secretion was collected for a total period of three hours by gastric intubation. Aspirations were performed every five minutes to insure completeness of collection, and the successive aspirates were combined into a single specimen for each hour. The volumes of these gastric collections were measured, and their acidities were determined by colorimetric microtitration using bromphenol blue and phenol red as indicators. Pepsin was determined by Bucher, Grossman, and Ivy's modification (4) of the Anson-Mirsky method (5), using lyophilized bovine hemoglobin powder in the substrate (6). Hourly rates of output of acid and pepsin were calculated from these volumes and concentrations.

\section{RESULTS}

The results of these experiments are recorded in Table I, where the hourly outputs of pepsin and acid are shown for each clinical category. For each group are given the range of values, the mean, and its standard deviation.

It is clear from these statistics that in the absence of obvious stimuli the duodenal ulcer group secreted three times as much pepsin as did the normal group. Although there is some overlap of the ranges of these two groups, the difference between their means is significant well below the $1 \%$ level $(\mathrm{t}=5.96, \mathrm{n}=45, \mathrm{P}<0.0001)$. The means for the small number of gastric cancer and gastric ulcer cases are statistically identical with those for the normal group.

This table also demonstrates that the duodenal ulcer group secreted five times as much acid per hour as did the normal group. Here again, the difference between their means is significant at the $1 \%$ level $(\mathrm{t}=4.48, \mathrm{n}=45, \mathrm{P}<0.0001)$, despite the overlap of their ranges.

When the hourly outputs of gastric pepsin are compared with the hourly outputs of acid in all 
TABLE I

Basal secretion of pepsin and acid in man

\begin{tabular}{|c|c|c|c|c|c|c|c|}
\hline \multirow{3}{*}{ Clinical category } & \multirow{3}{*}{$\begin{array}{l}\text { No. of } \\
\text { cases }\end{array}$} & \multicolumn{6}{|c|}{ Hourly output } \\
\hline & & \multicolumn{3}{|c|}{ Pepsin (Hgb unils) } & \multicolumn{3}{|c|}{$\mathrm{HCl}(m E q)$} \\
\hline & & Range & Mean & SDm & Range & Mean & $\mathrm{SDm}$ \\
\hline $\begin{array}{l}\text { Control } \\
\text { Duodenal ulcer } \\
\text { Gastric ulcer } \\
\text { Gastric cancer } \\
\text { Pernicious anemia }\end{array}$ & $\begin{array}{r}26 \\
21 \\
4 \\
5 \\
5\end{array}$ & $\begin{array}{r}0-8,335 \\
2,914-35,050 \\
5,314-11,215 \\
0-3,354 \\
0\end{array}$ & $\begin{array}{c}4,119^{* *} \\
14,241^{* *} \\
6,736 \\
1,512 \\
-\end{array}$ & $\begin{array}{l} \pm 2,881 \\
\pm 7,142 \\
\pm 2,954 \\
\pm 1,080\end{array}$ & $\begin{array}{r}0-1.67 \\
0.14-10.66 \\
0-3.62 \\
0-0.48 \\
0\end{array}$ & $\begin{array}{l}0.61^{*} \\
3.30^{*} \\
2.27 \\
0.15 \\
-\end{array}$ & $\begin{array}{l} \pm 0.50 \\
\pm 2.93 \\
\pm 1.37 \\
\pm 0.17 \\
-\end{array}$ \\
\hline
\end{tabular}

${ }^{*}$ For the difference of the means, $\mathrm{t}=4.48, \mathrm{n}=45, \mathrm{P}<0.0001$.

$* *$ For the difference of the means, $t=5.96, n=45, P<0.0001$

the individual subjects, a moderately high positive correlation $(\mathrm{r}=+0.86)$ is obtained. This correlation coefficient corresponds to a probability $P$-value of less than $0.1 \%(n=59, P<0.001)$. This relationship is illustrated graphically in the scatter diagram of Figure 1 , where the average hourly output of pepsin is plotted against that of acid; the straight line has been fitted by the method of least squares.

\section{DISCUSSION}

Since the basal gastric secretion was defined by $\operatorname{Lim}(1)$ as the juice secreted by the stomach in the absence of all intentional and avoidable stimuli, the

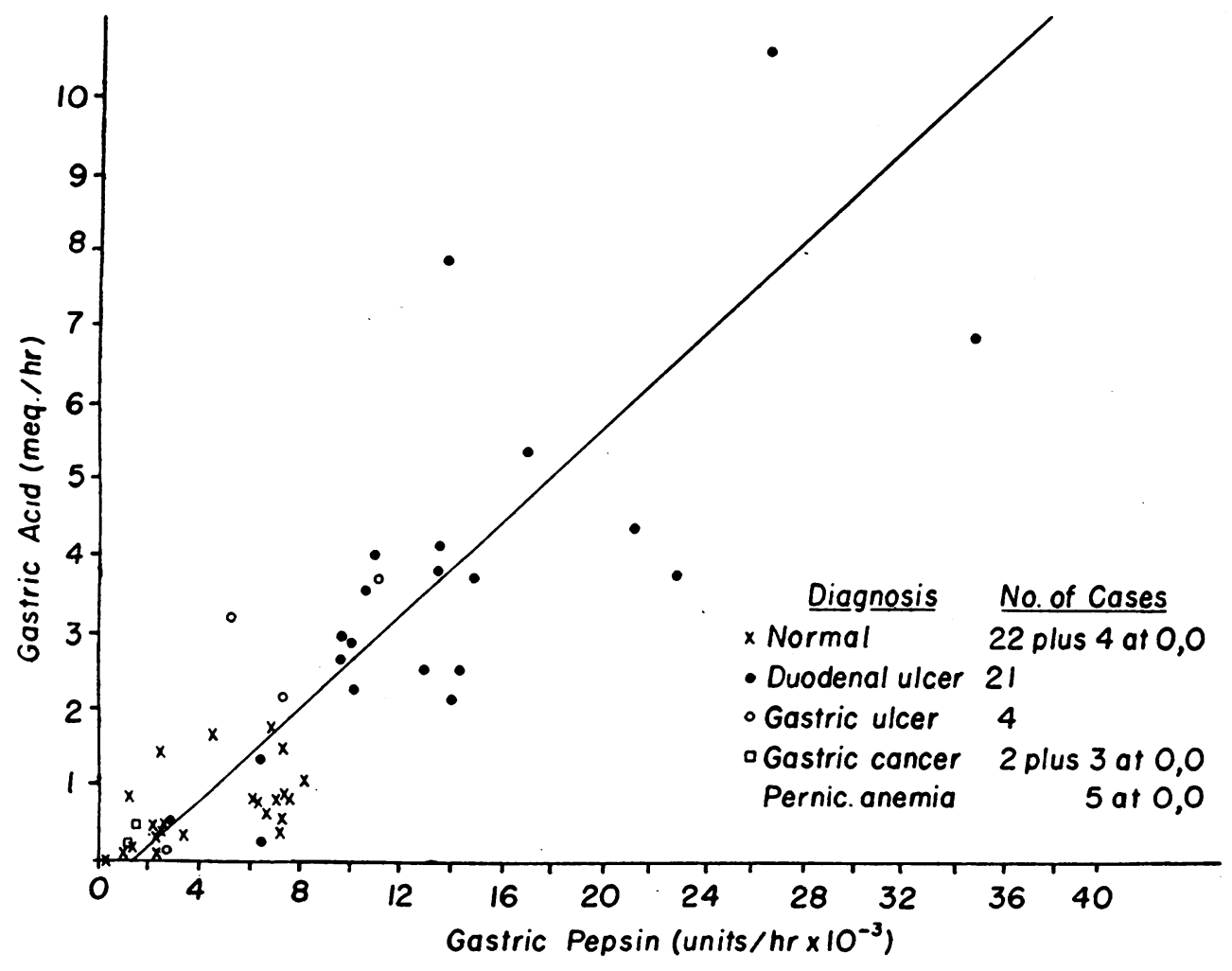

Fig. 1. Scatter Diagram Showing Relation of Gastric Secretion of Pepsin to Acid in 61 SUBJECTS

As indicated in the legend, there are 12 points which fall at the origin $(0,0)$ and are therefore not shown $(\mathrm{r}=+0.86, \mathrm{P}<0.0001)$. 
effort was made in the present study to measure secretion under basal conditions by keeping the subjects' stomachs at rest for 18 hours before starting collection, and performing the experiments in an isolated room.

The results obtained indicate that there is wide variation in the level of peptic secretory activity in the resting human stomach, ranging from 0 to 8,335 units per hour in the control group, and from 2,914 to 35,050 units per hour in the duodenal ulcer group. Despite the range of values observed for each of the clinical categories studied, it is clear that on the average the duodenal ulcer group secreted three times as much pepsin as did the normal group. The situation in regard to pepsin is thus exactly similar to that already demonstrated by Bloomfield and his associates (2) for the basal secretion of acid, and which we have also confirmed in the present study.

Of great interest is the finding that there is a significant degree of correlation between the amounts of pepsin and the amounts of acid being secreted by the resting human stomach, acid and enzyme varying directly with each other. Since $\mathrm{HCl}$ and pepsinogen are derived from separate cell types of the gastric glands, the implications of this correlation are intriguing. They suggest that the peptic cells and the parietal cells are responding to some common influence in the basal state. This common influence may perhaps be the intensity of vagal stimulation, as has been maintained by numerous investigators, but no conclusive evidence for this exists at present. Hunt (7) also has recently observed a correlation of the amount of pepsin, secreted in response to histamine and to a meal, with the amount of acid secreted in response to these stimuli. He has suggested also that this is consistent with the hypothesis that some common factor controls the reactivity of the parietal and peptic cells, a factor which he believes may be vascular in nature. This correlation of acid and pepsin secretion suggests, also, that there is no significant qualitative difference in the character of the secretion occurring in the stomach of patients with duodenal ulcer as compared with that which occurs in the normal individual. Rather, it indicates only a quantitative difference in their respective levels of secretory activity, the relative outputs of acid and pepsin tending to be the same in both categories of subjects. The present evidence is thus consistent with the generally held, but by no means proven, concept that there is hypervagal activity in the stomach of the duodenal ulcer patient.

\section{SUMMARY AND CONCLUSION}

1. The basal secretion of pepsin and acid was measured for periods of three hours in 61 individuals, comprising a wide range of secretory activity and a variety of clinical conditions.

2. Twenty-one duodenal ulcer patients secreted, on the average, three times as much pepsin per hour as did the 26 individuals of the control group without gastrointestinal lesions. A small group of four gastric ulcer and five carcinoma patients fell within the normal range of secretory behavior.

3. Similarly, increased secretion of acid also occurred in the duodenal ulcer group in the basal state.

4. A high degree of positive correlation was demonstrated between the amounts of pepsin and of acid secreted per hour, suggesting that in the basal state the peptic and the parietal cells are responding to some common influence, possibly of vagal origin.

\section{REFERENCES}

1. Lim, R. K. S., On the relationship between the gastric acid response and the basal secretion of the stomach. Am. J. Physiol., 1924, 69, 318.

2. Bloomfield, A. L., Chen, K. C., and French, L. R., Basal gastric secretion as a clinical test of gastric function with special reference to peptic ulcer. J. Clin. Invest., 1940, 19, 863.

3. Hollander, F., The composition and mechanism of formation of gastric acid secretion. Science, 1949, 110, 57.

4. Bucher, G. R., Grossman, M. I., and Ivy, A. C., A pepsin method: the role of dilution in the determination of peptic activity. Gastroenterology, 1945, $5,501$.

5. Anson, M. L., and Mirsky, A. E., Estimation of pepsin with hemoglobin. J. Gen. Physiol., 1932, 16, 59.

6. Orringer, D., Lauber, F. U., and Hollander, F., Use of dried bovine hemoglobin powder in the Anson and Mirsky methods for pepsin and trypsin. Science, 1950, 111, 88.

7. Hunt, J. N., An interpretation of the histamine test of gastric secretion. Gastroenterology, 1950, 16, 231. 